\title{
Optokinetic Stimulation Increases Corticotropin-Releasing Factor mRNA in Inferior Olivary Neurons of Rabbits
}

\author{
N. H. Barmack' and W. S. Young, III ${ }^{2}$ \\ 'Department of Ophthalmology, R. S. Dow Neurological Sciences Institute, Good Samaritan Hospital and Medical Center, \\ Portland, Oregon 97209, and 2Laboratory of Cell Biology, National Institute of Mental Health, Bethesda, Maryland 20892
}

\begin{abstract}
Stimulus-specific changes in levels of corticotropin-releasing factor (CRF) mRNA in inferior olivary neurons were studied in unanesthetized rabbits. The possible functional importance of CRF, a neuropeptide that is expressed in all inferior olivary neurons, in cerebellar synaptic transmission was investigated in a subpopulation of inferior olivary neurons, the caudal dorsal cap. Previous studies have shown that unidirectional, binocular optokinetic stimulation increases the level of discharge in neurons located in one of the caudal dorsal caps of the inferior olive and decreases the level of discharge in neurons in the opposite dorsal cap. We investigated the influence of prolonged (1-144 hr), unidirectional, binocular, optokinetic stimulus on the levels of CRF mRNA in dorsal cap neurons, measured with the technique of hybridization histochemistry.
\end{abstract}

Rabbits were placed at the center of a cylindrical optokinetic drum that rotated at a constant velocity of $5 \mathrm{deg} / \mathrm{sec}$, stimulating one eye in the posterior-to-anterior direction and the contralateral eye in the anterior-to-posterior direction. Posterior-to-anterior stimulation of the left eye evoked increased activity of inferior olivary neurons located in the right caudal dorsal cap. Conversely, anterior-to-posterior stimulation of the right eye evoked decreased activity of neurons in the left caudal dorsal cap.

The levels of CRF mRNA in dorsal cap neurons that were activated by prolonged optokinetic stimulation were increased by a factor of 4 to 7 after $48 \mathrm{hr}$ of stimulation and by more than a factor of 10 after $144 \mathrm{hr}$ of optokinetic stimulation. These optokinetically induced increases in CRF mRNA decayed to background levels after $30 \mathrm{hr}$. Our observations implicate CRF in visual olivocerebellar function and suggest that CRF may play a role in the plastic control of eye movement mediated by the visual olivocerebellar system.

The cerebellum receives afferent information from two major classes of inputs, mossy fibers and climbing fibers. Whereas mossy fibers originate from a number of different sources (Ito, 1984), climbing fibers (CFs) originate exclusively from the contralateral inferior olivary nucleus (Fox et al., 1967; Desclin,

\footnotetext{
Received Jun. 12, 1989; revised Aug. 14, 1989; accepted Aug. 15, 1989.

We thank Emily Shepard, Mary Westcott-Hodson, and Leta Wong for technical assistance. This research was supported by NEI EY04778 and the Oregon Lions Sight and Hearing Foundation.

Correspondence should be addressed to Neal H. Barmack, Ph.D., R. S. Dow Neurological Sciences Institute, 1120 N.W. 20th Ave., Portland, OR 97209.

Copyright (C) 1990 Society for Neuroscience $0270-6474 / 90 / 100631-10 \$ 02.00 / 0$
}

1974). Each cerebellar Purkinje cell receives a projection from a single CF terminal, which evokes a large EPSP, which in turn evokes multiple Purkinje cell action potentials (Granit and Phillips, 1956; Eccles et al., 1966).

One of the subdivisions of the inferior olive, the dorsal cap of Kooy, consists of a group of 1500-2000 neurons that encode visual stimulation in at least three different directions (Simpson et al., 1981). The most caudal aspect of the dorsal cap consists of a compact cluster of approximately 500 neurons, which encode horizontal optokinetic stimulation. Posterior-to-anterior optokinetic stimulation of the left eye excites neurons in the right caudal dorsal cap (Barmack and Hess, 1980a). Conversely, anterior-to-posterior optokinetic stimulation of the left eye causes a decreased discharge of neurons in the right caudal dorsal cap (Fig. 1, $A, B$ ). These visually responsive neurons in the dorsal cap have a maximal sensitivity to retinal slip velocity at 1.0 $\mathrm{deg} / \mathrm{sec}$, and this sensitivity is reduced by $50 \%$ at $0.1 \mathrm{deg} / \mathrm{sec}$ and at $10 \mathrm{deg} / \mathrm{sec}$ (Barmack and Hess, 1980a). The axons of these caudal dorsal cap neurons comprise part of the visual climbing fiber projection to the contralateral flocculus and nodulus (Maekawa and Simpson, 1973; Alley et al., 1975; Maekawa and Takeda, 1976).

The visual CF projection has been implicated in the normal control and plastic modification of reflexive eye movements (Dufosse et al., 1978; Barmack, 1979; Barmack and Hess, 1980a, b; Barmack and Simpson, 1980; Ito et al., 1976, 1982; Watanabe, 1984). If the dorsal cap is stimulated electrically, low velocity eye movements are evoked that outlast the duration of the electrical stimulus (Barmack and Hess, 1980b). If the dorsal cap is destroyed unilaterally, a permanent impairment in optokinetic reflexes mediated formerly by the damaged dorsal cap is induced (Barmack and Simpson, 1980). Prolonged unidirectional optokinetic stimulation at a retinal slip velocity of $1 \mathrm{deg} /$ sec, the velocity at which visual climbing fibers are most sensitive, evokes a prolonged "negative optokinetic afternystagmus," which can last for $100 \mathrm{hr}$ (Barmack and Nelson, 1987). These observations suggest that visual climbing fibers may, in part, be responsible for plastic cerebellar control of reflexive eye movements.

The role of visual climbing fibers in evoking plastic changes in cerebellar function may be dependent on the synthesis and/ or expression of synaptic transmitter(s). Although indirect evidence indicates that aspartate is an excitatory neurotransmitter of CFs (Wiklund et al., 1982; Matute et al., 1987), corticotropinreleasing factor (CRF), a 41 -amino acid neuropeptide that was isolated originally from bovinc hypothalamus (Vale et al., 1981) and that stimulates the release of proopiomelanocortin-derived 
Figure 1. Optokinetic stimulation and evoked activity in olivary neurons. $A$, Illustration of the location of the dorsal cap of the inferior olive within the rabbit brain stem. $B$, Microelectrode multineuron recording from the left dorsal cap of an anesthetized rabbit. The right eye was stimulated with a triangular waveform of constant velocity of $1 \mathrm{deg} /$ sec in the posterior-to-anterior and anterior-to-posterior directions. The bottom trace indicates the constant velocity optokinetic stimulus with respect to the contralateral eye. Posterior-to-anterior stimulation caused an increase in neuronal activity of caudal dorsal cap neurons. $C$, Illustration of the stimulus conditions for prolonged, binocular, unidirectional optokinetic stimulation. $D$, Illustration of flexible long-term head restraint system. Abbreviations: $\mathrm{Sp} \mathrm{Tr}$ $\mathrm{V}$, spinal trigeminal nucleus; $\mathrm{X}$, vagus nucleus; XII, hypoglossal nucleus; MAO, medial accessory olive; DAO, dorsal accessory olive; Cun $\mathrm{N}$, cuneate nucleus; B, $\beta$ nucleus; DC, dorsal cap; $P I$, pyramidal tract; LRN, lateral reticular nucleus.
A

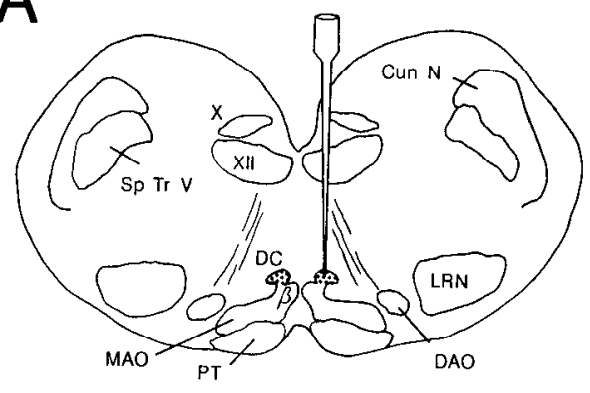

B
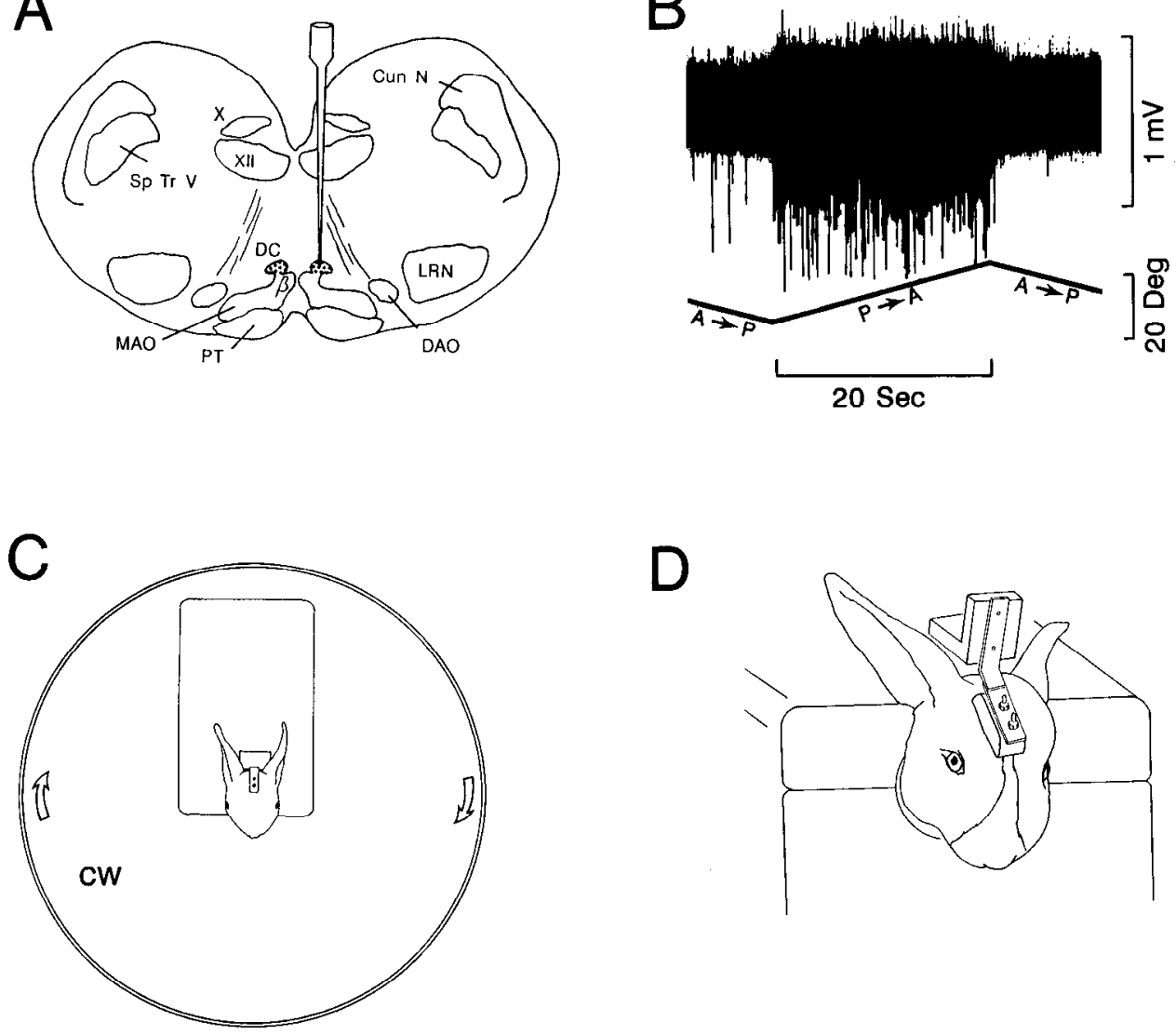

peptides from the anterior lobe of the pituitary gland, may also play a role in CF-Purkinje cell transmission. CRF has been localized immunohistochemically to several extrahypothalamic regions of the CNS, including the inferior olive and the cerebellum (Schipper et al., 1983; DeSouza, 1987; Palkovits et al., 1987; Powers et al., 1987; Sakanaka et al., 1987a, b; Cha and Foote, 1988; Cummings et al., 1988, 1989).

CRF mRNA also has been localized to the inferior olive using hybridization histochemistry (Young et al., 1986a; Palkovits et al., 1987). Receptors for CRF have been identified in the cerebellum (Wynn et al., 1984; DeSouza et al., 1985; DeSouza, 1987).

If CRF were functionally important for cerebellar synaptic transmission or for modification of synaptic transmission, one would expect that either the transcription of CRF mRNA or the expression of CRF in olivary neurons would be related to neuronal activity. We have examined one of these possibilities: the influence of naturally evoked olivary activity on the level of CRF mRNA in olivary neurons. We have used binocular optokinetic stimulation to alter the activity of neurons in the caudal dorsal cap of the inferior olive (Fig. 1) and we have examined the influence of this alteration in activity on levels of CRF mRNA using hybridization histochemistry. We have found that prolonged, binocular optokinetic stimulation increases levels of CRF mRNA in neurons of the "stimulated" dorsal caps relative to the background level of neurons in the "unstimulated" dorsal caps and relative to the background levels of CRF mRNA in other olivary neurons.

\section{Materials and Methods}

Surgical procedures. Twenty-six pigmented rabbits, weighing 1.0-2.0 $\mathrm{kg}$, were the subjects in this experiment. In preparatory operations, the rabbits were anesthetized with intramuscular injections of ketamine hydrochloride $(50 \mathrm{mg} / \mathrm{kg})$, xylazine $(6 \mathrm{mg} / \mathrm{kg})$, and acepromazine maleate $(1.2 \mathrm{mg} / \mathrm{kg})$. Each rabhit's head was aligned in a sterentaxic apparatus so that the lambda suture was $1.5 \mathrm{~mm}$ above the bregma suture. Two stainless steel screws (8-32) were anchored to the calvarium with 4 smaller, peripherally placed stainless steel screws (2-56) and dental cement. The 2 larger screws mated with devices that were used to restrain the rabbit's head during optokinetic stimulation. Rabbits recovered from surgery for at least $4 \mathrm{~d}$ before being exposed to prolonged optokinetic stimulation.

Optokinetic stimulation. For long-term optokinetic stimulation, rabbits were placed in a plastic restrainer (Nalgene) with an adjustable neckpiece. The restrainer had a stainless steel grid floor elevated above a plastic, removable collection pan. The restrainer was mounted on a pedestal in the center of an optokinetic cylinder with a diameter of 110 $\mathrm{cm}$ and a height of $115 \mathrm{~cm}$. The inside wall of the cylinder was a contourrich pattern that rotated (clockwise) at an angular velocity of $5 \mathrm{deg} / \mathrm{sec}$, stimulating the left eye in the posterior-to-anterior direction (exiting neurons in the right dorsal cap) and the right eye in the anterior-toposterior direction (disfacilitating neurons in the left dorsal cap) (Fig. 1C). Optokinetic stimulation initially evokes optokinetic eye movements with an average velocity of $4 \mathrm{deg} / \mathrm{sec}$, thereby creating a retinal slip velocity of $1 \mathrm{deg} / \mathrm{sec}$ (Erickson and Barmack, 1980).

During optokinetic stimulation, the head of the rabbit was aligned within the optokinetic cylinder in the horizontal plane by a springloaded flexible coupling that was attached to the rabbit restrainer and that had holes that mated with the surgically implanted bolts on the calvarium (Fig. 1D). This flexible coupling system permitted movements of the head in the sagittal plane but prevented the potentially confounding influence of optokinetically evoked horizontal head move- 
The Journal of Neuroscience, February 1990, 10(2) 633

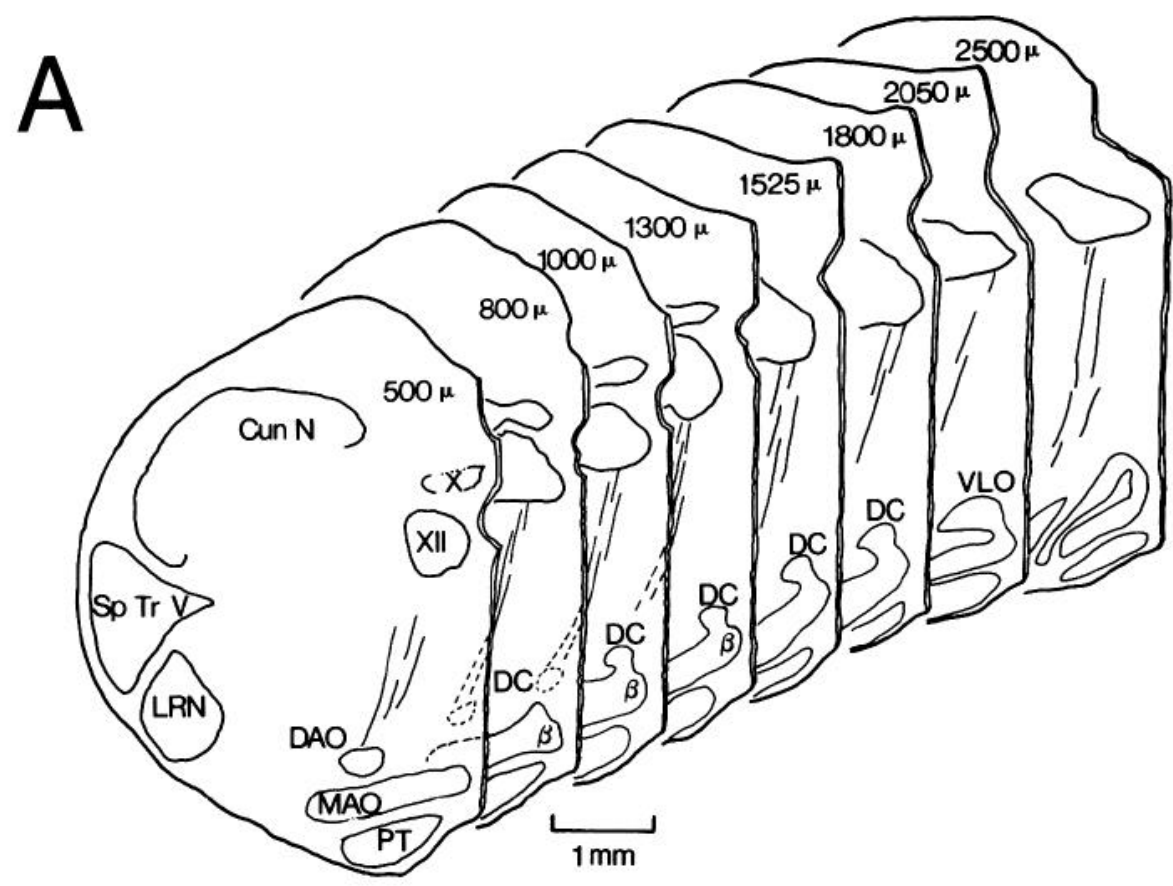

B
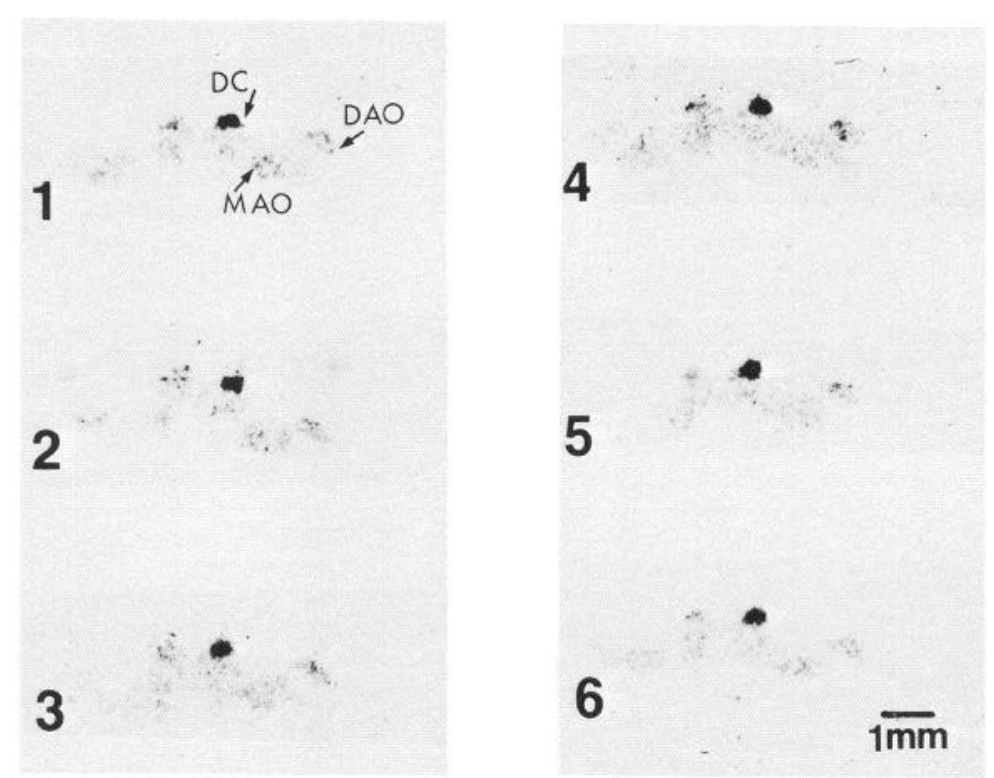

Figure 2. The location of optokinetically evoked increases of CRF mRNA in the caudal dorsal cap of the inferior olive. $A$, An illustration of the rostralcaudal extent of the dorsal cap. $B, \mathrm{X}$-ray films taken of six, $14-\mu \mathrm{m}$, serial sections through the caudal inferior olive of R121. This area corresponds to the shaded region of the dorsal cap illustrated in $1 A$. These sections are spaced $28 \mu \mathrm{m}$ apart and are numbered from most caudal (1) to most rostral (6). The rabbit received $43 \mathrm{hr}$ of binocular optokinetic stimulation in the posterioranterior direction with respect to the left eye. The increase in grain density over the right dorsal cap corresponds to a $440 \%$ increase in levels of CRF mRNA in neurons of the right dorsal cap. Scale bars, $1 \mathrm{~mm}$.

ments. The flexible coupling also maintained the head in a relatively constant orientation with respect to earth horizontal (Barmack and Nelson, 1987). The alignment of the head within the optokinetic cylinder was critical, since even slight misalignments resulted in vertical as well as horizontal optokinetic stimulation. In electrophysiological experiments, slight misalignments of the head caused changes in olivary discharge in rostral regions of the dorsal cap during horizontal optokinetic stimulation. These same neurons responded optimally to vertical optokinetic stimulation. The sign of this horizontally evoked change in activity could be reversed by altering the angle of pitch of the rabbit's head by $2-4$ deg (unpublished observations).

The method of restraint used in this experiment caused no pressure on any part of the body. It permitted partial movement of the head in the sagittal plane, and it permitted vertical and lateral movement of the body. The rabbit was able to maintain its normal posture, with all four paws in contact with the support surface. The EKG and respiratory rate of several rabbits were monitored during the experiment and remained within the normal range of $180-220$ beats $/ \mathrm{min}$ and $30-50$ breaths $/ \mathrm{min}$.
Both rates accelerated if the rabbit was disturbed from its normal state of quiet rest by an unexpected stimulus.

During optokinetic stimulation, the rabbits were removed from the apparatus every $8 \mathrm{hr}$, weighed, and given food and water. They were returned to the testing apparatus after $20-30 \mathrm{~min}$. The feeding period was terminated only when the rabbits had finished feeding and had withdrawn to the rear of the feeding cage. This feeding regimen of 20 $30 \mathrm{~min}$ every $8 \mathrm{hr}$ was sufficient for the rabbits to maintain body weight, which was measured three times each day. Rabbits easily adapted to this modified restraint and evinced no behavioral signs that would indicate a reluctance to resubmit to restraint after a brief hiatus for food and water.

One might expect that prolonged optokinetic stimulation would induce nausea in the stimulated rabbits. However, rabbits lack an emetic reflex. Furthermore, their ingestion of ordinary rabbit food was undiminished by prolonged stimulation. Prolonged stimulation did produce some postural changes when the rabbits were released from the optokinetic drum, including transient circling behavior in the direction op- 


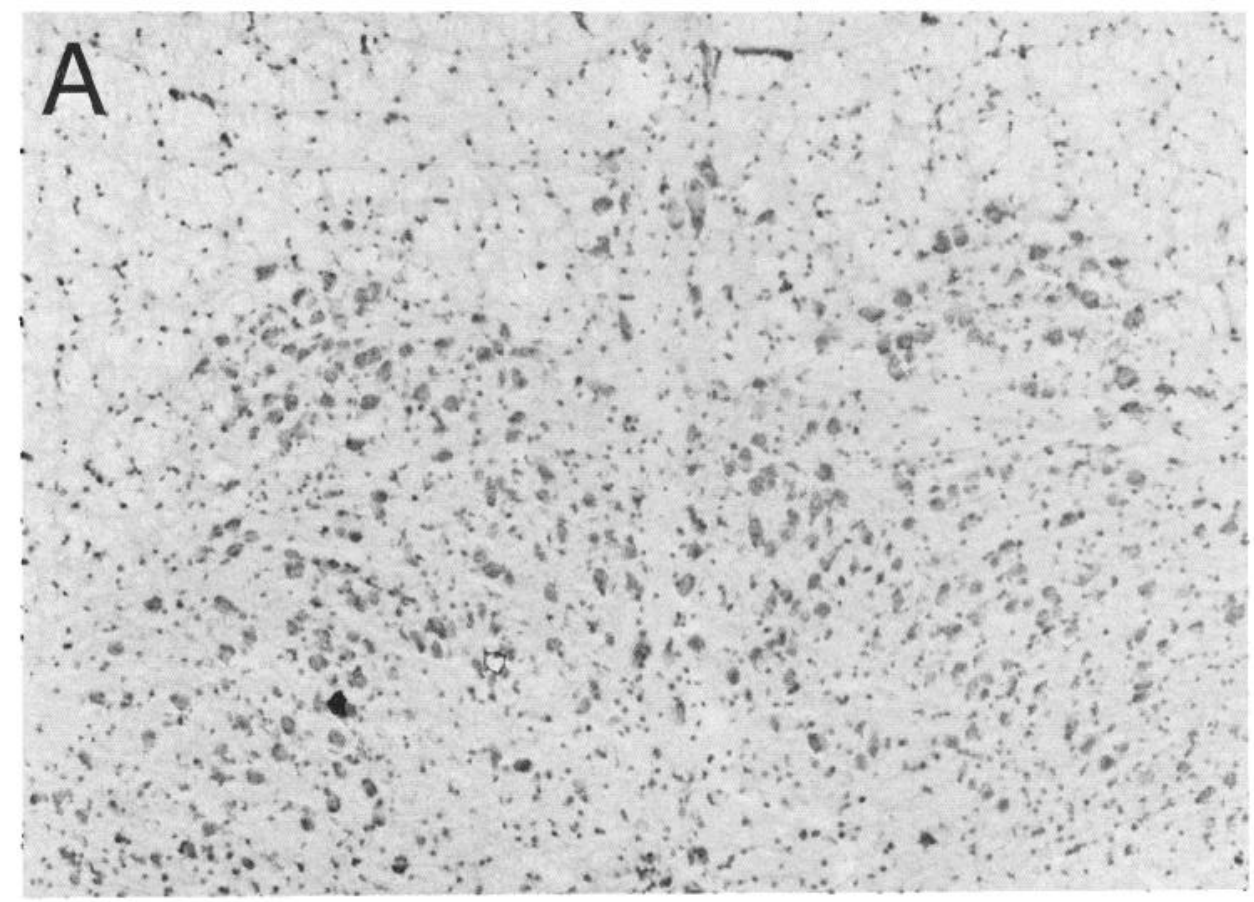

Figure 3. Optokinetically induced increase in CRF mRNA in caudal dorsal cap revealed by darkfield photomicrograph of an emulsion-coated brain-stem section. R126 received $37 \mathrm{hr}$ of binocular optokinetic stimulation in the posterior to anterior direction with respect to the left eye, causing a $360 \%$ increase in levels of CRF mRNA in the right dorsal cap. $A, B$, Brightfield and darkfield views of the same tissue section are shown. The finer spatial resolution of the emulsion demonstrates clustering of silver grains over individual olivary neurons. Scale bar, $200 \mu \mathrm{m}$.

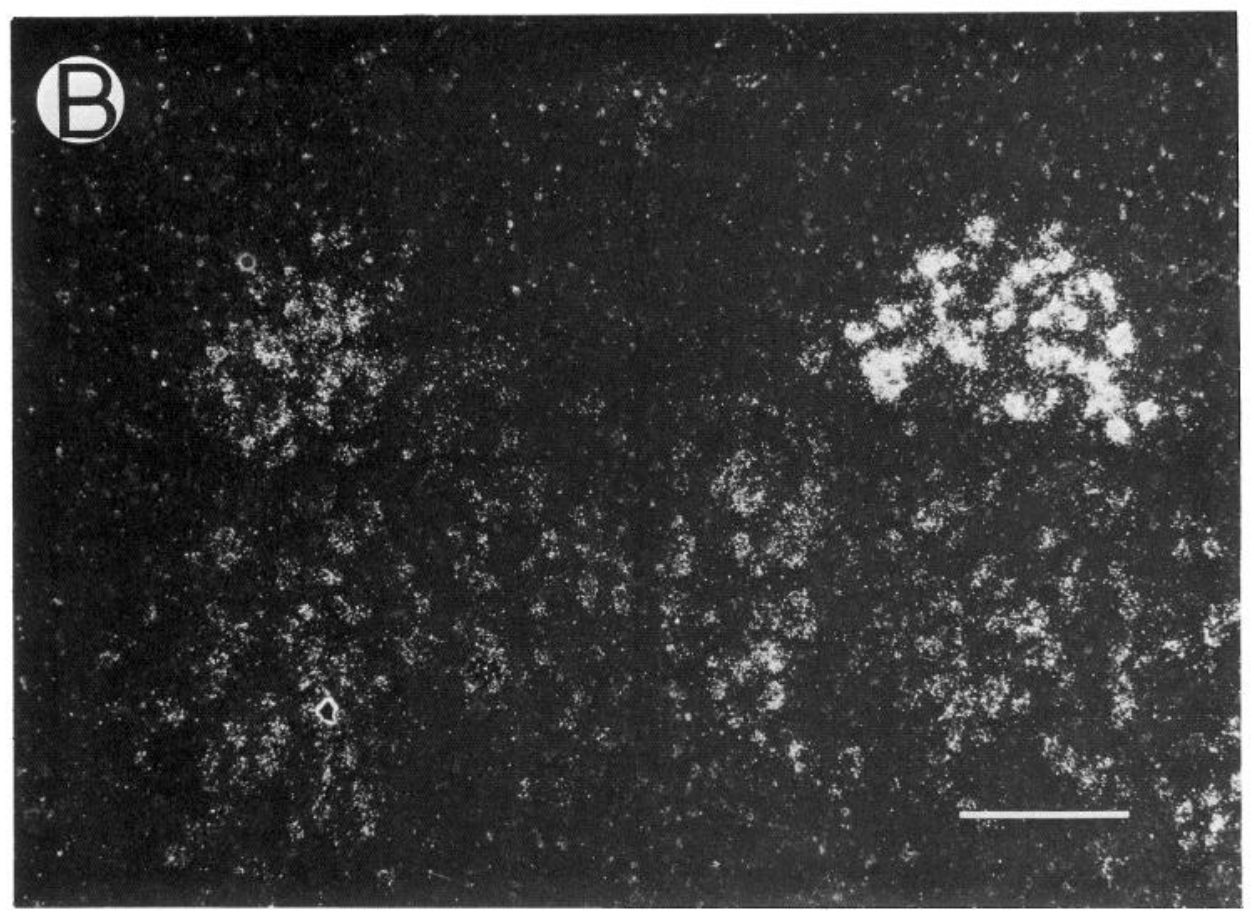

posite to the drum rotation. This circling behavior disappeared after 1$3 \mathrm{~min}$ and was replaced by slow ocular and head nystagmus, which lasted 1-30 min. The nystagmus could be suppressed by rabbits as they were eating and drinking.

Hybridization histochemistry. At the conclusion of optokinetic stimulation, rabbits were anesthetized (sodium pentobarbital, $60 \mathrm{mg} / \mathrm{kg}$ ). The brains were quickly removed and frozen in isopentane cooled on dry ice. Frozen brain sections $(12-14 \mu \mathrm{m})$ were cut on a cryostat, thawmounted onto slides, and hybridized with a ${ }^{35} \mathrm{~S}$-labeled oligonucleotide probe for CRF, which was complementary to the coding region for amino acids $22-37$ of rat CRF (Young et al., 1986b). The CRF probe had a specific activity of $0.5-1.5 \times 10^{4} \mathrm{Ci} / \mathrm{mmol}$ and was dissolved in the hybridization buffer at $1 \times 10^{6} \mathrm{dpm} / 50 \mu \mathrm{l}$. The complex buffer contained $4 \times \operatorname{SSC}(1 \times \mathrm{SSC}=0.15 \mathrm{~m}$ sodium chloride and $15 \mathrm{~mm}$ sodium citrate, $\mathrm{pH} 7.2$ ) and $50 \%$ formamide. Hybridization was performed $20-24 \mathrm{hr}$ at $37^{\circ} \mathrm{C}$. The washes were performed in $2 \times \mathrm{SSC}$ and $50 \%$ formamide at $40^{\circ} \mathrm{C}$ over $1 \mathrm{hr}$, with four changes. The density of silver grains on the $\mathrm{x}$-ray film images of these sections was subsequently analyzed with a computer-based Loats image analysis system (Westminster, MD; Young et al., 1986b). Quantification of the amount of CRF probe hybridized to each section through the dorsal cap was achieved by codeveloping sections of brain paste standards of equal thickness containing known concentrations of ${ }^{35} \mathrm{~S}$ (Young et al., 1986b; Lightman and Young, 1987). The baseline, unstimulated level of CRF probe that 

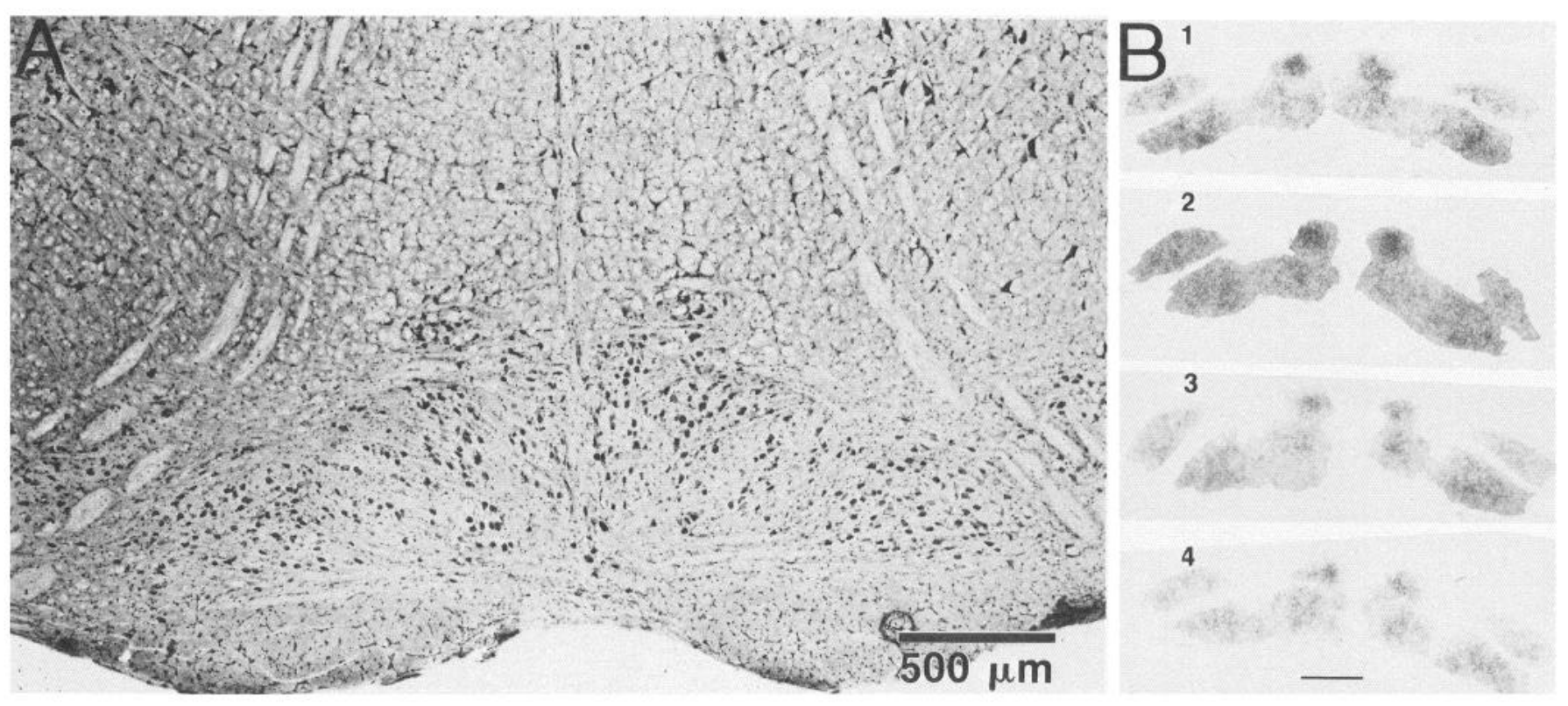

Figure 4. Absence of change in levels of CRF mRNA in caudal dorsal cap neurons in an optokinetically unstimulated rabbit. R151 was restrained within the optokinetic drum for a period of $48 \mathrm{hr}$. While the rabbit was in the drum, pingpong ball hemispherical occluders were suspended over each eye, preventing optokinetic stimulation. $A$, Photomicrograph of brain stem at the level of the caudal dorsal cap. $B$, X-ray films taken from four sections spaced about $200 \mu \mathrm{m}$ apart in the caudal (1) to rostral (4) levels. Section 2 corresponds to the level at which the photomicrograph was taken. Scale bars, $500 \mu \mathrm{m}$.

was hybridized to the region of the caudal dorsal cap taken from a rabbit that did not receive optokinetic stimulation was $7700 \pm 372$ copies $( \pm$ SEM, R151; see Fig. 4). Measurements were taken over four regions of brain stem sections that encompassed the caudal inferior olive: the left and right dorsal caps and the left and right medial accessory olives. The measurements of these circumscribed regions within each histological section (dorsal cap, medial accessory olive) were multiplied by the area of each region before obtaining ratios of different regions. This accounted for the known greater spread of autoradiographic signal at higher concentrations of radioactivity. Ratios of dorsal cap measurements were compared across different rabbits because of rabbit-to-rabbit variability in hybridization values from the medial accessory olive. This variability could be due to tissue section thickness, postmortem dissection time, and duration of storage.

In two experiments, the slides on which brain sections were mounted were coated with a photographic emulsion, NTB3 (Eastman Kodak, Rochester, NY). These slides were stored for 2 weeks before they were developed.

\section{Results}

Optokinetically evoked increase in levels of CRF $M R N A$ in dorsal cap neurons

Binocular, unidirectional optokinetic stimulation at a stimulus velocity of $5 \mathrm{deg} / \mathrm{sec}$ caused an increase in levels of CRF mRNA in neurons in the caudal dorsal cap that was contralateral to the eye that was stimulated in the posterior-to-anterior direction (Figs. 2, 3). Although there was a relative increase in CRF mRNA in the caudal dorsal cap contralateral to the eye that received posterior-to-anterior optokinetic stimulation, there was no stimulus-evoked relative decrease in the ipsilateral caudal dorsal cap. This was determined by measuring level of probe hybridized in each dorsal cap relative to that in the adjacent medial accessory olive. The level of probe hybridized over the unstimulated dorsal cap relative to that over medial accessory olive in rabbits that had received at least $12 \mathrm{hr}$ of unidirectional binocular optokinetic stimulation was $1.08, \mathrm{SD}=0.29, n=17$. The cellular composition of the caudal dorsal cap is much more homoge- neous and its boundaries are much more distinct than are those of the medial accessory olive. Consequently, measurements of probe hybridized over the dorsal caps were less variable than measurements of either the medial accessory olives. Measurements reported here are ratios of probe hybridized over the stimulated dorsal cap relative to the unstimulated dorsal cap.

Optokinetically evoked increases in levels of CRF mRNA in the caudal dorsal cap were not observed in rabbits that were restrained within the optokinetic drum while wearing pingpong ball optical occluders and, therefore, received no optokinetic stimulation (Fig. 4). If the direction of rotation of the optokinetic drum was changed from clockwise to counterclockwise so that the right eye was stimulated in the posterior-to-anterior direction and the left eye was stimulated in the anterior-to-posterior direction, the increased levels of CRF mRNA appeared over the left dorsal cap.

In 2 initial experiments before the flexible head coupling was adjusted to obtain the optimal horizontal orientation of the heads of the rabbits in the sagittal plane, the heads of the rabbits were tilted nose-up by approximately $7 \mathrm{deg}$. In these cases, horizontal rotation of the optokinetic drum provided a downward vertical component to the visual field of the left eye and an upward vertical component to the visual field of the right eye. This misaligned optokinetic stimulus not only caused increased CRF mRNA in the caudal right dorsal cap but also caused increased CRF mRNA about $600 \mu \mathrm{m}$ more rostral in the left dorsal cap, ipsilateral to the eye stimulated in the posterior-to-anterior direction (Fig. 5). Neurons of this region have vertically directionally selective components in the structure of their optokinetic receptive fields (Leonard et al., 1988).

Three other oligonucleotide probes were made that successfully identified mRNAs of somatostatin, galanin, and enkephalin in the brains of rats but did not label cells in the inferior olive above background activity (Fig. 6). The somatostatin probe 

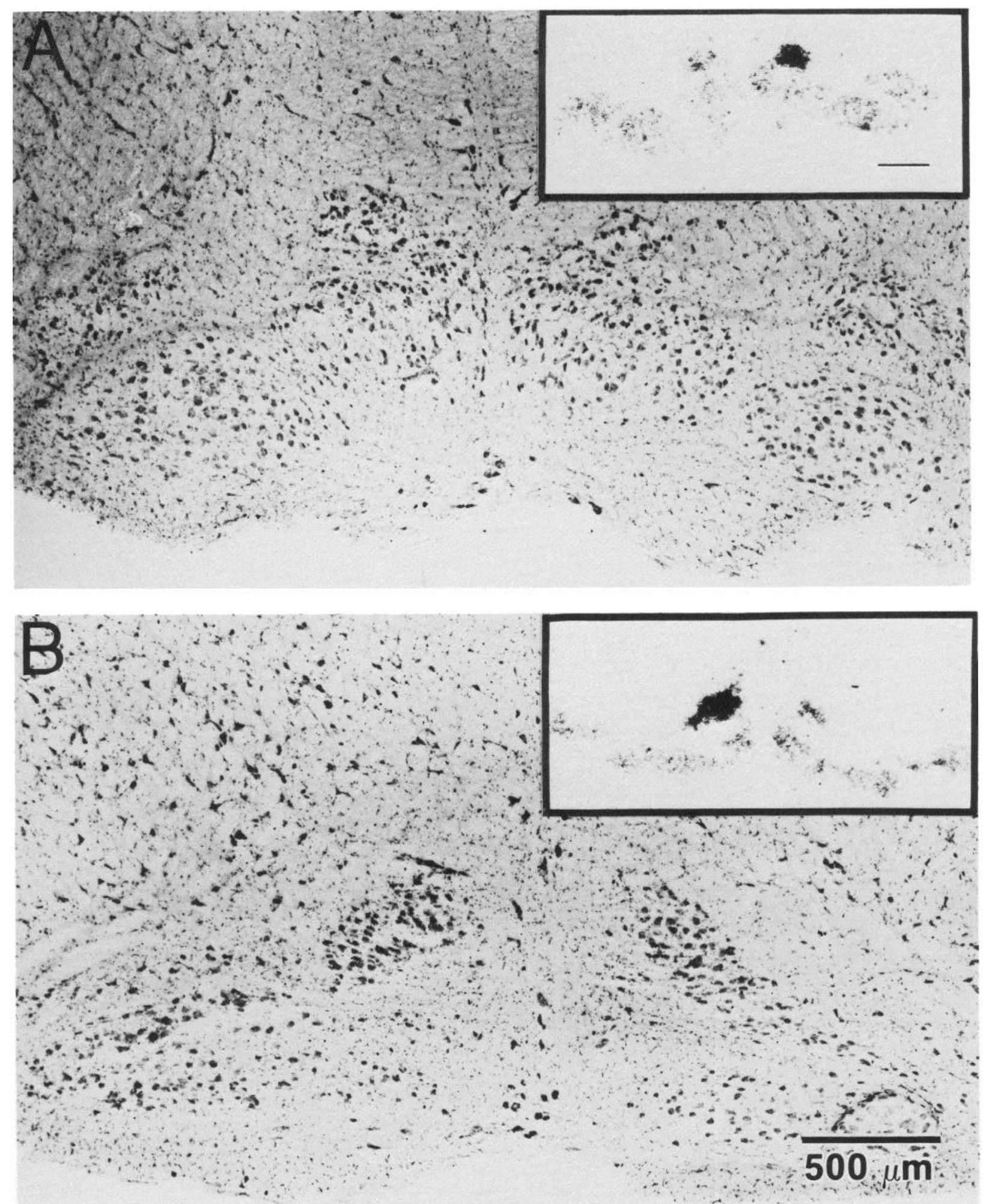

Figure 5. Optokinetically evoked changes in levels of CRF mRNA in caudal and rostral dorsal cap neurons. R120 received $22 \mathrm{hr}$ of unidirectional, binocular optokinetic stimulation that was posterior-to-anterior with respect to the left eye. However, the flexible head coupling was misaligned, producing a 7 degree nose-up head tilt. This misalignment produced a downward vertical component to the posterior-to-anterior optokinetic stimulation of the left eye and an upward vertical component to the anterior-to-posterior optokinetic stimulation of the right eye. $A$, Brain-stem section at the level of the caudal dorsal cap. Inset shows X-ray films at level of the caudal dorsal cap. Note increased silver grain density over the left dorsal cap. $B$, Brain-stem section at the level of the rostral dorsal cap near the ventrolateral outgrowth. Note the increased silver grain density over the right dorsal cap. 

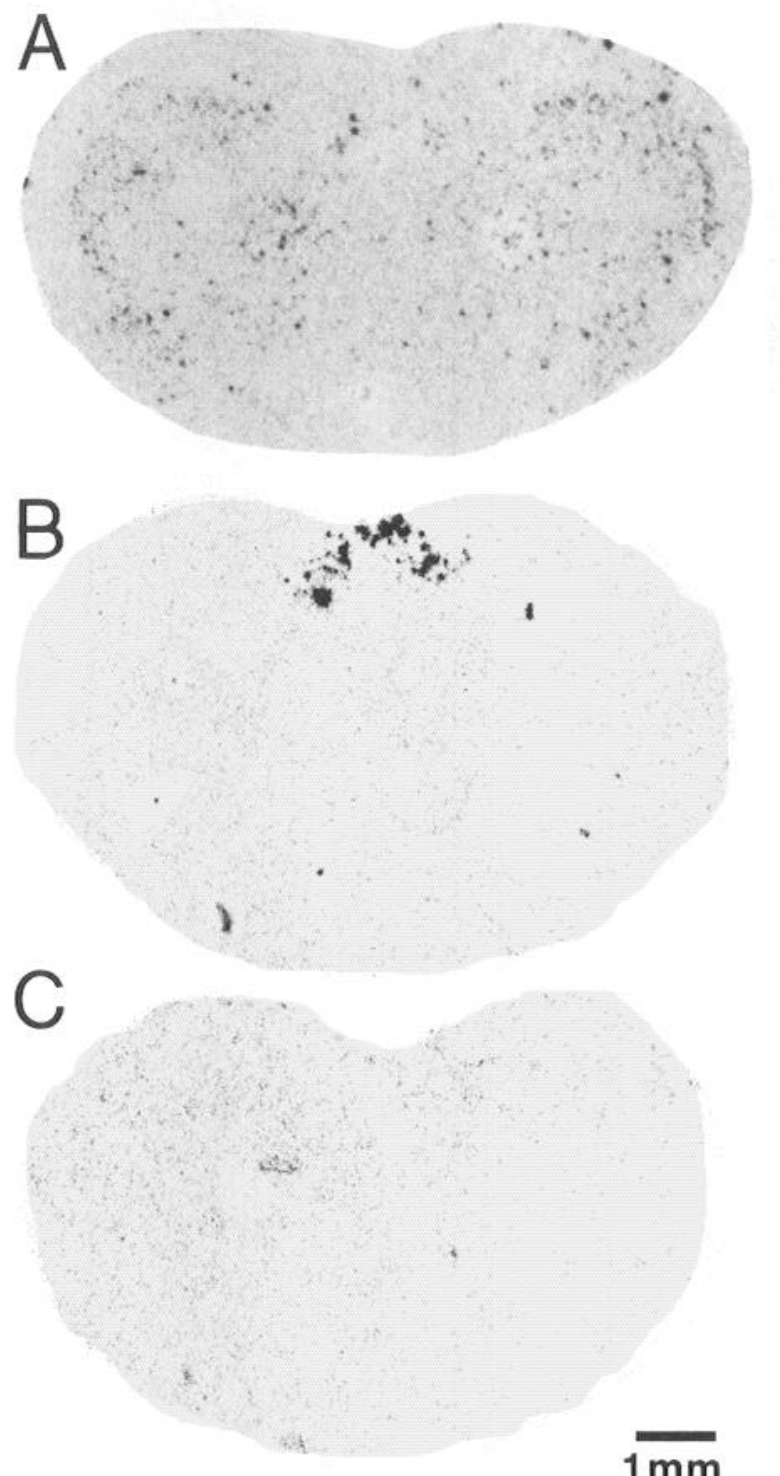

Figure 6. Absence of labeling of inferior olivary ncurons by oligonucleotide probes for somatostatin, galanin, and enkephalin. The probe for somatostatin $(A)$ labeled cells in the trigeminal complex and cuneate nucleus. The galanin probe $(B)$ labeled cells in the tractus solitarius-vagal complex. This area is shown in higher magnification in $D$. The probe for enkephalin $(C)$ did not cause any labeling above background levels. The area of the inferior olive that corresponds to the level of the brain stem represented in the X-ray films was at the level of the caudal dorsal cap $(E)$.

labeled cells in the spinal trigeminal complex and cuneate nucleus (Fig. 6A). The probe for galanin labeled cells in the nucleus tractus solitarius-vagal complex at the level of the caudal dorsal cap (Fig. 6B). The enkephalin probe did not label any structure at the level of the caudal dorsal cap (Fig. $6 \mathrm{C}$ ). A messenger sense vasopressin probe of the same length and similar guanine-cytosine content as the CRF mRNA probe also failed to label cells in the inferior olive above background activity.

\section{Time course of optokinetically induced increase in CRF $m R N A$ in dorsal cap neurons}

Six hours of binocular unidirectional optokinetic stimulation were necessary in order to detect any change in the labeling of caudal dorsal cap neurons by the CRF probe. After $48 \mathrm{hr}$ of optokinetic stimulation, there were 4-7-fold increases in levels of CRF mRNA in the stimulated caudal dorsal caps. After 140 $\mathrm{hr}$ of optokinetic stimulation, there was a 10 -fold increase in levels of CRF mRNA in the stimulated dorsal cap (Fig. 7). These optokinetically evoked increases in levels of CRF mRNA in the stimulated dorsal cap were nonmonotonic. After approximately $96 \mathrm{hr}$ of binocular optokinetic stimulation, the level of CRF mRNA actually decreased. This decrease could be attributed to a change in the optokinetically evoked eye movements, which in turn influenced the retinal slip velocity of the optokinetic stimulus. After $48 \mathrm{hr}$ of stimulation, the gain of the optokinetic reflex decreased, and in some cases a reversed nystagmus (negative optokinetic afternystagmus) was evoked even though the optokinetic drum remained illuminated (Barmack and Nelson, 1987). This nystagmus prevented a constant retinal slip velocity of $1 \mathrm{deg} / \mathrm{sec}$, the velocity at which dorsal cap neurons are maximally sensitive, from being maintained (Barmack and Hess, 1980a). 


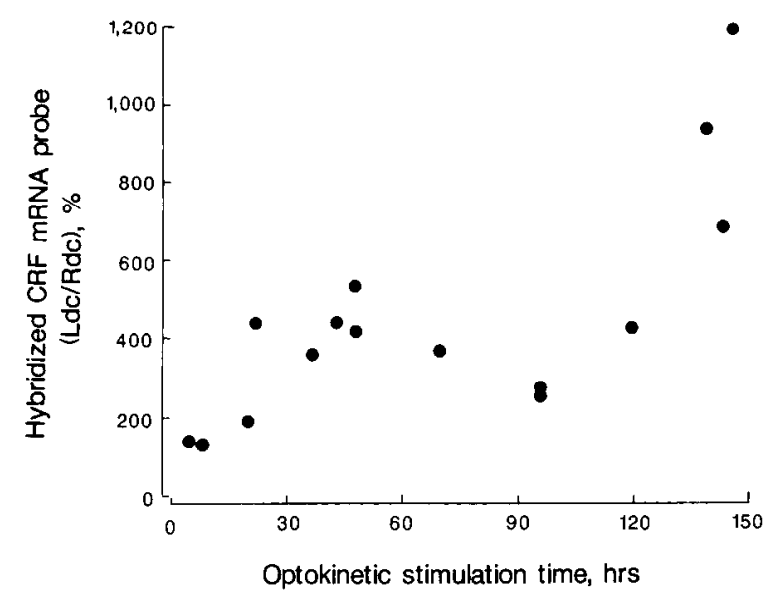

Figure 7. Time course of the induction of the CRF mRNA increase. The ratio of hybridized CRF probe in neurons of the optokinetically stimulated and unstimulated dorsal caps is shown as a function of the duration of the binocular optokinetic stimulation. Each data point represents measurements from five or six brain-stem sections from one rabbit.

\section{Decay of increased levels of CRF $m R N A$ in dorsal cap neurons}

Having observed a 4-7-fold increase in levels of CRF mRNA in dorsal cap neurons after $48 \mathrm{hr}$ of optokinetic stimulation, we attempted to measure the time course of decay from this elevated level in the absence of further optokinetic stimulation. Rabbits were optokinetically stimulated for a fixed time (44-48 hr). Pingpong ball occluders were then placed over the eyes of the restrained rabbit for a variable period of time, providing a relatively contour-free visual field with the same ambient illumination and preventing additional optokinetic stimulation. There was a rapid decrease in the levels of CRF mRNA in the stimulated dorsal cap during the first $10 \mathrm{hr}$ after termination of optokinetic stimulation (Fig. 8). The levels of CRF mRNA in the stimulated and disfacilitated dorsal caps were nearly equal 24-30 hr after the termination of optokinetic stimulation.

\section{Discussion}

Optokinetically evoked increases in CRF $m R N A$ : methodological considerations

Optokinetic stimulation evokes large changes in CRF mRNA in a population of neurons in the caudal dorsal cap of the inferior olive even when such stimulation only modestly increases the normally low spontaneous discharge rate of CFs from 1-2 impulses/sec to 3 impulses/sec. Three lines of evidence suggest that the oligonucleotide probe that was used was specific for CRF mRNA. First, the distribution of regions of the brains of rabbits, rats, and humans in which this probe has been identified as containing CRF mRNA agrees with the distribution of neurons that have been identified with immunocytochemical techniques (Schipper et al., 1983; DeSouza, 1987; Palkovits et al., 1987; Powers et al., 1987; Sakanaka et al., 1987a, b; Cummings et al., 1988). Second, oligonucleotide probes for galanin, somatostatin, and enkephalin failed to label cells in the inferior olive (Fig. 6). Third, using a messenger sense vasopressin probe of the same length and similar guaninc-cytosine content as the CRF mRNA probe, no signal was observed above a homogeneous background level.

The minimum duration of optokinetic stimulation necessary

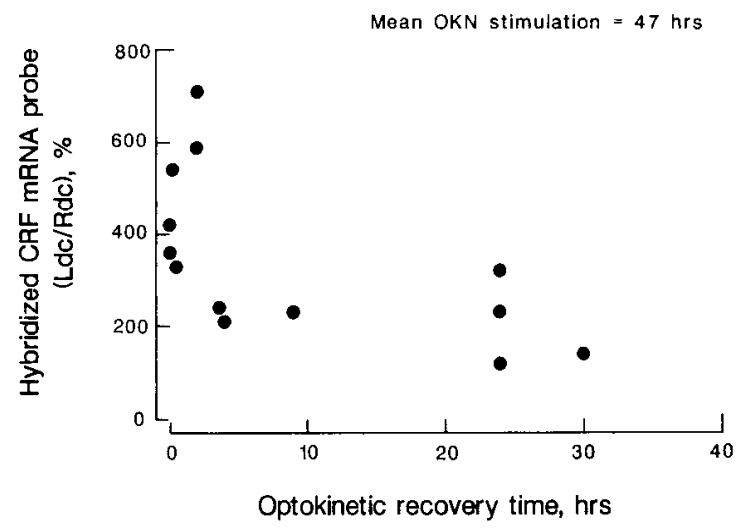

Figure 8. Decay of induced increase of CRF mRNA following a constant period of binocular optokinetic stimulation. Rabbits were exposed to a constant duration of optokinetic stimulation of 44-48 hr. Further optokinetic stimulation was prevented by placing pingpong ball occluders over the eyes of the rabbits. After a variable period of time, the rabbits were killed, and the decay in the relative levels of hybridized CRF probe in the dorsal caps was determined.

for evoking increases in CRF mRNA appears to be $6 \mathrm{hr}$. At present, we have not found a stimulus duration at which the optokinetically evoked increase reaches an asymptotic value. It is likely that further increases in the duration of optokinctic stimulation would evoke even larger increases in the level of CRF mRNA in the stimulated dorsal cap.

Obviously, improvements in the conditions of stimulation would help to reduce some of the variability in the data that has been collected. For example, it would be possible to use feedback from an eye position signal to control the movement of the optokinetic drum and thereby control the exact retinal slip velocity of the optokinetic pattern on the retina. It might also be possible to monitor the state of consciousness of the rabbits that receive prolonged continuous optokinetic stimulation. Nevertheless, even without these experimental refinements, the optokinetically evoked increase in levels of CRF mRNA suggests that this neuropeptide plays an important role in olivocerebellar synaptic transmission.

At present, we do not know whether the optokinetically increascd levels of CRF mRNA can be attributed to increased transcription or decreased degradation of CRF mRNA. A nuclear runoff transcription assay would be necessary to detect changes in transcription. However, this technique is inappropriate for in vivo experimentation and requires, at a minimum, $5 \times 10^{6}$ nuclei (Greenberg, 1989). The caudal dorsal cap contains only $5 \times 10^{2}$ neurons.

\section{Possible mechanisms underlying optokinetically evoked increased CRF $m R N A$ levels}

A greater understanding of the cellular transduction mechanisms that cause elevated levels of CRF mRNA depends on more controlled experimental conditions in which it would be possible to identify and modify concentrations of neurotransmitters that are released by presynaptic terminals on olivary neurons during optokinetically induced excitation. Alternatively, it is possible that the transduction is a more general electrogenically mediated phenomenon, which is independent of specific synaptic transmitters. For example, it would be of interest to learn if an increase in levels of CRF mRNA could be evoked 
by antidromic activation of climbing fibers at the level of the cerebellum.

\section{Possible role of CRF in olivocerebellar plasticity}

If the optokinetically evoked increase in levels of CRF mRNA is accompanied by a similar increase in the expression of CRF at climbing fiber terminals, it is possible that the release of this peptide and its binding to CRF receptors on Purkinje cells (Wynn et al., 1984; DeSouza et al., 1985; DeSouza, 1987) might contribute to both the short-term and long-term CF-cvoked modulation of the discharge of Purkinje cells and to the consequent plasticity of eye movements evoked by visual olivocerebellar activity.

Although cerebellar Purkinje cells are endowed with CRF receptors, the mechanisms by which altered expression of CRF could influence either immediate or long-term Purkinje cell activity is not understood. The exogenous application orCRF onto pyramidal cells in hippocampal tissue slices appears to cause an increase in the spontaneous discharge rate by reducing afterhyperpolarizations (Aldenhoff et al., 1983). Intraventricular injections of CRF in the anesthetized rat also increase the spontaneous discharge rate of neurons in the locus coeruleus (Valentino and Foote, 1988). However, in neither of these instances is it certain that the CRF-evoked increases in discharge rate were CRF receptor-mediated. In frontal cortex, as well as the amygdala, CRF receptors appear to be coupled to adenylate cyclase (Wynn et al., 1984), but the functional role of adenylate cyclase in either short-term or long-term signal transduction remains speculative.

It is possible that CRF could influence the responses of cerebellar Purkinje cells mediated by receptors for other synaptic transmitters that may be coreleased with CRF. For example, cerebellar Purkinje cells are endowed with quisqualate receptors (Kano et al., 1988; Kano and Kato, 1988). When glutamate is iontophoretically applied to Purkinje cells in conjunction with climbing fiber input, there is a subsequent long-term depression (LTD) of Purkinje cell responses to iontophoretically applied glutamate or to responses evoked by electrical stimulation of parallel fibers (Crepel and Krupa, 1988; Kano et al., 1988; Kano and Kato, 1988). This LTD also can be induced in vitro in immature rat cerebella by the application of phorbol esters, in conjunction with iontophoretic application of glutamate, presumably through a phorbol ester-induced activation of protein kinase C (Crepel and Krupa, 1988). At least four different subtypes of protein kinase $\mathrm{C}$ are expressed in the mammalian cerebellum (Coussens et al., 1986; Knopf et al., 1986; Brandt et al., 1987; Huang et al., 1987a, b; Shearman et al., 1987; Hidaka et al., 1988; Young, 1988). These observations suggest both spccific receptors and cellular transduction mechanisms that would be worth further examination with regard to the possible action of CRF on Purkinje cells.

\section{References}

Aldenhoff, J. B., D. L. Gruol, J. Rivier, W. Vale, and G. R. Siggins (1983) Corticotropin-releasing factor decreases postburst hyperpolarizations and excites hippocampal neurons. Science 221: 875-877.

Alley, K., R. Baker, and J. I. Simpson (1975) Afferents to the vestibulocerebellum and the origin of the visual climbing fibers in the rabbit. Brain Res. 98: 582-589.

Barmack, N. H. (1979) Immediate and sustained influences of visual olivocerebellar activity on eye movement. In Posture and Movement, R. E. Talbott and D. R. Humphrey, eds., pp. 123-167, Raven, New York.
Barmack, N. H., and D. T. Hess (1980a) Multiple-unit activity evoked in dorsal cap of inferior olive of the rabbit by visual stimulation. $J$. Neurophysiol. 43: 151-164.

Barmack, N. H., and D. T. Hess (1980b) Eye movements evoked by microstimulation of dorsal cap of inferior olive in the rabbit. J. Neurophysiol. 43: 165-181.

Barmack, N. H., and B. J. Nelson (1987) Influence of long-term optokinetic stimulation on eye movements of the rabbit. Brain Res. 437: $111-120$.

Barmack, N. H., and J. I. Simpson (1980) Effects of microlesions of dorsal cap of inferior olive of rabbits on optokinetic and vestibuloocular reflexes. J. Neurophysiol. 43: 182-205.

Brandt, S. J., J. E. Niedel, R. M. Bell, and W. S. Young III (1987) Distinct patterns of expression of different protein kinase $\mathrm{C}$ mRNAs in rat tissues. Cell 49: 57-63.

Cha, C. I., and S. L. Foote (1988) Corticotropin-releasing factor in olivocerebellar climbing-fiber system of monkey (Saimiri sciureus and Macaca fascicularis): Parasagittal and regional organization visualized by immunohistochemistry. J. Neurosci. 8: 4121-4137.

Coussens, L., P. J. Parker, L. Rhee, T. L. Yang-Feng, E. Chen, M. D. Waterfield, U. Francke, and A. Ullich (1986) Multiple, distinct forms of bovine and human protein kinase $\mathrm{C}$ suggest diversity in cellular signaling pathways. Science $233: 859-866$.

Crepel, F., and M. Krupa (1988) Activation of protein kinase Cinduces a long-term depression of glutamate sensitivity of cerebellar Purkinje cells. An in vitro study. Brain Res. 158: 397-401.

Cummings, S., B. Sharp, and R. Elde (1988) Corticotropin-releasing factor in cerebellar afferent systems: A combined immunohistochemistry and retrograde transport study. J. Neurusci. 8: 543-554.

Cummings, S. L., W. S. Young III, G. A. Bishop, E. B. DeSouza, and J. S. King (1989) Distribution of corticotropin-releasing factor in the cerebellum and precerebellar nuclei of the opossum: A study utilizing immunohistochemistry, in situ hybridization histochemistry, and receptor autoradiography. J. Comp. Neurol. 280: 501-521.

Desclin, J. C. (1974) Histological evidence supporting the inferior olive as the major source of cerebellar climbing fibers in the rat. Brain Res. 77: $365-384$.

DeSouza, E. B. (1987) Corticotropin-releasing factor receptors in the rat central nervous system: Characterization and regional distribution. J. Neurosci. 7: 88-100.

DeSouza, E. B., T. R. Insel, M. H. Perrin, J. Rivier, W. W. Vale, and M. J. Kuhar (1985) Corticotropin-releasing factor receptors are widely distributed within the rat central nervous system: An autoradiographic study. J. Neurosci. 5: 3189-3203.

Dufosse, M., M. Ito, and Y. Miyashita (1978) Diminution and reversal of eye movements induced by local stimulation of rabbit cerebellar flocculus after partial destruction of the inferior olive. Exp. Brain Res. 33: $139-141$.

Eccles, J. C., R. Llinas, and K. Sasaki (1966) The excitatory synaptic action of climbing fibers on the Purkinje cells of the horizontal and vertical optokinetic reflexes of the rabbit. J. Physiol. (Lond.) 182: 268-296.

Erickson, R. G., and N. H. Barmack (1980) A comparison of the horizontal and vertical optokinetic reflexes of the rabbit. Exp. Brain Res. 40: 448-456.

Fox, C. A., D. E. Hillmann, K. A. Siegesmund, and C. R. Dutta (1967) The primate cerebellar cortex: A Golgi and electron microscopic study. In Progress in Brain Research: The Cerebellum, C. A. Fox and R. S. Snider, eds., pp. 174-225, Elsevier, New York.

Granit, K., and C. G. Phillips (1956) Excitatory and inhibitory processes acting upon individual Purkinje cells of the cerebellum in cats. J. Physiol. (Lond.) 133: 520-547.

Greenberg, M. E. (1989) Identification of newly transcribed RNA. In Current Protocols in Molecular Biology, F. M. Ausubel, R. Brent, R. F. Kingston, D. D. Moore, J. G. Seidman, J. A. Smith, and K. Struhl, eds., pp. 1-8, Wiley, New York.

Hidaka, H., T. Tanaka, K. Onoda, M. Hagiwara, M. Watanabe, $\dot{H}$. Ohta, Y. Ito, M. Tsurudome, and T. Yoshida (1988) Cell typespecific expression of protein kinase $\mathrm{C}$ isozymes in the rabbit cerebellum. J. Biol. Chem. 263: 4523-4526.

Huang, F. L., Y. Yoshida, H. Nakabayashi, J. L. Knopl, W. S. Young III, and K.-P. Huang (1987a) Immunochemical identification of protein kinase $\mathrm{C}$ isozymes as products of discrete genes. Biochem. Biophys. Kes. Commun. 149: 946-952.

Huang, F. L., Y. Yoshida, H. Nakabayashi, and K.-P. Huang (1987b) 
Differential distribution of protein kinase $\mathrm{C}$ isozymes in the various regions of brain. J. Biol. Chem. 262: 15714-15720.

Ito, M. (1984) The Cerebellum and Neural Control, Raven, New York.

Ito, M., N. Nisimaru, and M. Yamamoto (1976) Pathways for the vestibulo-ocular reflex excitation arising from semicircular canals of rabbits. Exp. Brain Res. 24: 257-271.

Ito, M., P. J. Jastreboff, and Y. Miyashita (1982) Specific effects of unilateral lesions in the flocculus upon eye movements in albino rabbits. Exp. Brain Res. 45: 233-242.

Kano, M., and M. Kato (1988) Mode of induction of long-term depression at parallel fibre-Purkinje cell synapses in rabbit cerebellar cortex. Neurosci. Res. 5: 544-556.

Kano, M., M. Kato, and H. S. Chang (1988) The glutamate receptor subtype mediating parallel fibre-Purkinje cell transmission in rabbit cerebellar cortex. Neurosci. Res. 5: 325-337.

Knopf, J. L., M.-H. Lee, L. A. Sultzman, R. W. Kriz, C. R. Loomis, R. M. Hewick, and R. M. Bell (1986) Cloning and expression of multiple protein kinase C cDNAs. Ccll 46: 491-502.

Leonard, C. S., J. I. Simpson, and W. Graf (1988) Spatial organization of visual messages of the rabbit's cerebellar flocculus. I. Typology of inferior olive neurons of the dorsal cap of Kooy. J. Neurophysiol. 60: 2073-2090.

Lightman, S. L., and W. S. Young III (1987) Vasopressin, oxytocin, dynorphin, enkephalin and corticotrophin-releasing factor mRNA stimulation in the rat. J. Physiol. (Lond.) 394: 23-39.

Maekawa, K., and J. I. Simpson (1973) Climbing fiber responses evoked in vestibulocerebellum of rabbit from visual system. J. Neurophysiol. 36: 649-666.

Maekawa, K., and T. Takeda (1976) Electrophysiological identification of the climbing and mossy fiber pathways from the rabbit's retina to the contralateral cerebellar flocculus. Brain Res. 109: 169-174.

Matute, C., L. Wiklund, P. Streit, and M. Cucnod (1987) Sclective retrograde labeling with $\mathrm{D}$ - $[3 \mathrm{H}]$-aspartate in the monkey olivocerebellar projection. Exp. Brain Res. 66: 445-447.

Palkovits, M., C. Leranth, T. Gorcs, and W. S. Young (1987) Corticotropin-releasing factor in the olivocerebellar tract of rats: Demonstration by light and electron microscopic immunohistochemistry and in situ hybridization histochemistry. Proc. Natl. Acad. Sci. USA 84: 3911-3915.

Powers, R. E., E. B. DeSouza, L. C. Walker, D. L. Price, W. W. Vale, and W. S. Young III (1987) Corticotropin-releasing factor as a transmitter in the human olivocerebellar pathway. Brain Res. 415: 347352.

Sakanaka, M., T. Shibasaki, and K. Lederis (1987a) Corticotropinreleasing factor-like immunoreactivity in the rat brain as revealed by a modified cohalt-glucose oxidase-diaminobenzidine method. J. Comp. Neurol. 260: 256-298.

Sakanaka, M., T. Shibasaki, and K. Lederis (1987b) Corticotropinreleasing factor-containing afferents to the inferior colliculus of the rat brain. Brain Res. 414: 68-76.

Schipper, J., W. M. Steinbusch, I. Vermes, and F. J. H. Tilders (1983) Mapping of CRF-immunoreactive nerve fibers in the medulla oblongata and spinal cord of the rat. Brain Res. 267: 145-150.

Shearman, M. S., Z. Naor, U. Kikkawa, and Y. Nishizuka (1987) Differential expression of multiple protein kinase C subspecies in rat central nervous tissue. Biochem. Biophys. Res. Commun. 147: 911919.

Simpson, J. I., W. Graf, and C. Leonard (1981) The coordinate system of visual climbing fibers to the flocculus. In Progress in Oculomotor Research, A. F. Fuchs and W. Becker, eds., pp. 475-484, Elsevier, North Holland, Amsterdam.

Vale, W., J. Spiess, C. Rivier, and J. Rivier (1981) Characterization of a 41 -residue ovine hypothalamic peptide that stimulates secretion of corticotropin and beta-endorphin. Science 213: 1394-1397.

Valentino, R. J., and S. L. Foote (1988) Corticotropin-releasing hormone increases tonic but not sensory-evoked activity of noradrenergic locus coeruleus neurons in unanesthetized rats. J. Neurosci. 8: 10161025.

Watanabe, E. (1984) Neuronal events correlated with long-term adaptation of the horizontal vestibulo-ocular reflex in the primate flocculus. Brain Res. 297: 169-174.

Wiklund, L., G. Toggenburger, and M. Cuenod (1982) Aspartate: Possible neurotransmitter in cerebellar climbing fibers. Science $216: 78-$ 79.

Wynn, P. C., R. L. Hauger, M. C. Holmes, M. A. Millan, K. J. Catt, and G. Aguilera (1984) Brain and pituitary receptors for corticotropin releasing factor: Localization and differential regulation after adrenalectomy. Peptides 5: 1077-1084.

Young, W. S., III (1988) Expression of three (and a putative four) protein kinase $C$ genes in brains of rat and rabbit. J. Chem. Neuroanat. 1: $177-194$.

Young, W. S., III, L. C. Walker, R. E. Powers, E. B. DeSouza, and D. L. Price (1986a) Corticotropin-releasing factor mRNA is expressed in the inferior olives of rodents and primates. Mol. Brain Res. $1: 189-$ 192.

Young, W. S., III, E. Mezey, and R. E. Siegel (1986b) Quantitative in situ hybridization histochemistry reveals increased levels of corticotropin-releasing factor mRNA after adrenalectomy in rats. Neurosci. Lett. 70: 198-203. 